\title{
Radiation doses during cardiac catheterisation procedures in India: a multicentre study
}

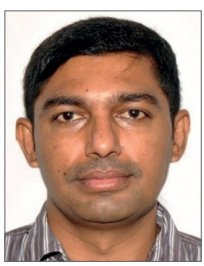

Vijayakumar Subban ${ }^{1 *}, \mathrm{MD}, \mathrm{DM}, \mathrm{FNB}$; Sophie Amelot ${ }^{2}, \mathrm{MS}$;

Suma M. Victor ${ }^{1}$, DNB, DNB, FNB; Anil Potdar ${ }^{3}$, MD, DNB, MNAMS, FACC, FSCAI;

Vishawanath Yadav³, MBBS, DNB, DNB; Tejas Patel ${ }^{4}$, MD, DM, FACC, FSCAI;

Sanjay $\mathrm{Shah}^{4}$, MD, DM; Thomas Alexander ${ }^{5}, \mathrm{MD}$, DM, FACC, FICC, FCSI;

Balakumaran Jeyakumaran ${ }^{5}$, MD, DM; Juno Angel ${ }^{1}$, MSc, PGDCR;

Mullasari S. Ajit ${ }^{1}$, MD,DM,FRCP

1. Institute of Cardiovascular Diseases, The Madras Medical Mission, Chennai, India; 2. GE Healthcare, Buc, France;

3. Parisoha Heart Foundation Pvt.Ltd, Mumbai, India; 4. Apex Heart Institute, Ahmedabad, India; 5. Kovai Medical Centre and Hospital, Coimbatore, India

This paper also includes supplementary data published online at: www.asiaintervention.org

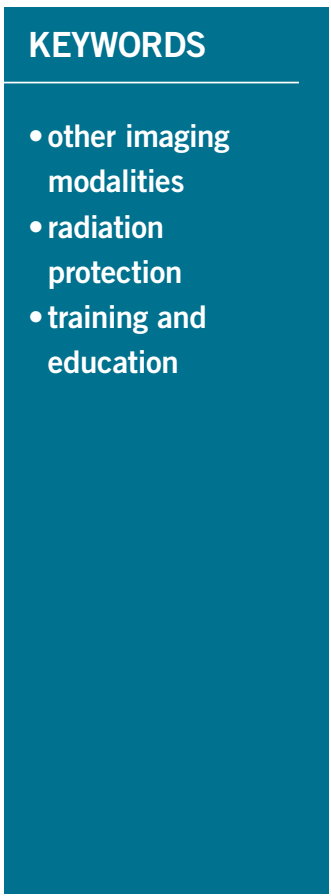

\section{Abstract}

Aims: Established, evidence-based measures of radiation are required to minimise its hazards, while maintaining adequate image quality. The aim of this study is to evaluate radiation data and generate reference radiation levels for commonly performed coronary catheterisation procedures in India.

Methods and results: In this prospective, observational study, all procedures were performed in accordance with the established standards using Innova IGS 520/2100-IQ catheterisation laboratories. Demographic, procedural and radiation data were collected. Dose reference limits (DRL) were established as the $75^{\text {th }}$ percentile of the total distribution. There were 2,906 coronary angiograms (CAG), 750 percutaneous coronary interventions (PCI) and $715 \mathrm{CAG}+\mathrm{PCI}$. DRLs for dose area product were: $19.6 \mathrm{~Gy} \cdot \mathrm{cm}^{2}$ for $\mathrm{CAG}, 49.8 \mathrm{~Gy} \cdot \mathrm{cm}^{2}$ for PCI and $72.0 \mathrm{~Gy} \cdot \mathrm{cm}^{2}$ for CAG+PCI, respectively. Median cumulative air kerma levels were: $185 \mathrm{mGy}$ for CAG, 533mGy for PCI, and $891 \mathrm{mGy}$ for CAG+PCI. Male gender, higher BMI, combining $\mathrm{CAG}+\mathrm{PCI}$, fluoroscopy time, number of cine frames, and image acquisition settings were significant contributors to increased radiation dose.

Conclusions: This study established reference radiation dose levels for diagnostic and interventional coronary procedures in India, which were comparable to and in the lower range of international standards.

*Corresponding author Institute of Cardiovascular Diseases, The Madras Medical Mission, 4-A, Dr. J Jayalalitha Nagar, Moggappair, Chennai 600037, India.E-mail: drkumarvijay@gmail.com 


\section{Abbreviations}

BMI body mass index

CAG coronary angiography

CAK cumulative air kerma

DAP dose area product

FT fluoroscopy time

$\mathbf{P C l}$ percutaneous coronary intervention

\section{Introduction}

Radiation-based imaging has revolutionised the practice of modern medicine. Though it is used extensively in various fields of medicine, it remains the predominant modality for imaging in the cardiac catheterisation laboratory. However, these procedures place both the patient and the laboratory personnel at risk from ionising radiation. Excessive exposure to ionising radiation may have a deterministic effect from direct injury to skin or a stochastic effect in the form of neoplasms ${ }^{1}$. Professional societies have emphasised the need to develop radiation safety programmes for catheterisation laboratories, which include parties responsible for protection and safety, training/education of staff, radiation monitoring and protective shielding ${ }^{2,3}$. Guidelines have proposed a dose threshold of 5 Gy or $500 \mathrm{~Gy} \cdot \mathrm{cm}^{2}$, beyond which patients must be monitored for skin injuries ${ }^{2}$.

In India, approximately 1,000 hospitals offer cardiovascular catheterisation facilities. The number of coronary interventional procedures increased from 177,240 in 2012 to 373,579 in $2016^{4}$. An estimated $30 \%$ of these are multivessel or complex interventional procedures. In addition, approximately 30,000 non-coronary interventions are performed yearly and the number of diagnostic procedures is close to thrice the number of all other procedures performed ${ }^{4}$. Though there has been a steady growth in the number of catheterisation laboratories and procedures over the years, systematic reporting of patient radiation doses is not practiced in India. The aim of this study is to establish a baseline radiation reference dose for commonly performed coronary catheterisation procedures in India and to compare them with established international standards.

\section{Methods}

\section{STUDY DESIGN AND POPULATION}

This prospective observational study was conducted at four prominent tertiary cardiac centres across India. From June 2015 to January 2017, 4,603 consecutive patients undergoing diagnostic and interventional coronary procedures were prospectively included in the study. All the procedures were performed in accordance with the participating centres' established internal standards. Procedures were categorised into the following three groups: Group I, coronary angiography (CAG); Group II, percutaneous coronary intervention (PCI); Group III, coronary angiography followed by ad hoc percutaneous coronary intervention $(\mathrm{CAG}+\mathrm{PCI})$. Other procedures such as peripheral, endovascular, structural, electrophysiological, or paediatric catheterisation were excluded. This study was approved by an ethical review board, and all patients signed an informed consent prior to the procedure. The study was registered with Clinical Trial Registry-India (CTRI), reference number: CTRI/2015/11/006359.

\section{IMAGING EQUIPMENT}

All procedures were performed using 3 Innova IGS 520 and 2 Innova 2100-IQ catheterisation laboratories (GE Healthcare, Chicago, IL, USA), installed between 2011 and 2015. All systems offered similar capability to customise dose and image quality among 5 "dose personalisation" settings according to the preference of individual institution. The choice of configurable settings, as well as the selection of acquisition frame rates and normal versus low dose level preference was left to the physician's discretion. Together, configurable settings and selectable operational settings provided a typical 6:1 range in fluoroscopy and cine dose rate adjustment capability. The configurations of the system and selectable settings of acquisition protocols with radiation dose limit (RDL) used at the different hospitals are summarised in Supplementary Table 1. All systems provided built-in dosimetry capability, to monitor patient radiation data throughout the procedure.

\section{DATA COLLECTION}

The following data were prospectively collected for each procedure: baseline demographics, clinical characteristics of the patient, radiation dose indicators from the system at the end of the procedure (dose area product [DAP, Gy. $\left.\mathrm{cm}^{2}\right]$ ) and cumulative air kerma [CAK, mGy], fluoroscopy time [FT, minutes]), as well as other procedural data such as procedure type, access route, number of vessels treated, number of stents implanted, duration of the procedure, procedural complications, quantity of contrast, use of adjunctive technology such as intravascular imaging, fractional flow reserve assessment and rotational atherectomy. In addition to the patient radiation data, other parameters such as acquisition mode, frame rate, radiation exposure data split between fluoroscopy and cine $\mathrm{x}$-ray acquisition duration, and number of cine exposures were automatically recorded for each x-ray acquisition and were analysed. For comparison between institutions, DAP rates were used to normalise differences in procedural time, which might be attributed to differences in operator experience or complexity of the procedure ${ }^{5}$. For each type of procedure, radiation data reference levels (RLs) were established as the third quartile of the total distribution ${ }^{6}$. For this study, the $75^{\text {th }}$ percentile of the distribution of DAP values was defined as dose reference level (DRL).

\section{STATISTICAL ANALYSIS}

Statistical analysis was performed using Microsoft ${ }^{\circledR}$ Excel $^{\mathbb{R}}$ 2010 (Version 14.0.7165.5000) and Minitab ${ }^{\circledast} 17$ statistical software (2010) (Version 17.3.1; Minitab, State College, PA, USA). Categorical variables are presented as numbers and percentages. Continuous variables are described with mean \pm standard deviation or median (with interquartile range) depending on their distribution. Kruskal-Wallis test was used for one-way 
analysis of variance for comparison of radiation data between sites. Comparison of radiation data was performed using the onesided non-parametric one sample sign test, when referenced data were provided as median, to test the null hypothesis that no difference would be found between study and reference median and with the alternative hypothesis that the study median would be lower than the reference median. Similarly, when referenced data was provided as mean, a one sample t-test was used. Multivariate analysis was performed for the patient subset of coronary interventions (PCI and $\mathrm{CAG}+\mathrm{PCI}$ ) to identify individual risk factors with logarithm-transformed DAP as the dependent variable using back-ward stepwise analysis. All the patient-related and image acquisition-related characteristics listed above were used as covariates. Beta-coefficients are given after re-transformation (exp [beta coefficient]) to describe the relative influence of each variable on DAP. A 95\% confidence level was used for all statistical calculations and a p-value of 0.05 or less was considered significant.

\section{Results}

Overall 4,603 patients were included in the study. Of these 4,371 had analysable data (195 incomplete radiation datasets, and 37 excluded from analysis as other types of procedures). Procedure distribution, demographic profile, cardiovascular risk factors and indications for the procedure are summarised in Table 1. The majority of patients were male (71\%). Diabetes and hypertension were prevalent at $39 \%$ and $42 \%$, respectively. Most of the procedures were performed electively $(69 \%)$. The impact of BMI on radiation is depicted in Figure 1, and there is a stepwise increase in DAPs in both PCI and CAG+PCI groups across increasing BMIs. This trend, however, is not seen in the CAG group. Procedural data are shown in Table 2. The transradial technique was used in $76 \%$ of the patients. There were 2,906 CAGs, 750 PCIs and 715 CAG+PCIs. Adjunctive technologies were used in $99(2.9 \%)$ patients. On an average, there were $1.2 \pm 0.4$ vessels treated and $1.3 \pm 0.6$ stents implanted per each therapeutic procedure.

Procedure specific radiation data are summarised in Table 3. Reference levels for DAP, CAK and FT from the study for the above procedures were: $19.6 \mathrm{~Gy} \cdot \mathrm{cm}^{2}, 325 \mathrm{mGy}, 4.5 \mathrm{~min}$ for CAG; $49.8 \mathrm{~Gy} \cdot \mathrm{cm}^{2}$, $1016 \mathrm{mGy}, 18.2 \mathrm{~min}$ for PCI; and $72.0 \mathrm{~Gy} \cdot \mathrm{cm}^{2}$, $1461 \mathrm{mGy}, 15.1 \mathrm{~min}$ for CAG+PCI, respectively. As expected, both DAP level, CAK level, and number of cine frame rates were higher when ad hoc PCI was performed. Male gender, higher BMI, combining $\mathrm{CAG}+\mathrm{PCI}$, fluoroscopy time, number of cine frames, and image acquisition settings were significant contributors to increased radiation dose (Table 4). Among the fluoroscopy settings, using '7.5 fps RDL+Low' significantly decreased DAPs while '15 fps Smart IQ Low' did not show any statistical significance. On the other hand, 15 fps with either 'Normal or Smart IQ Normal' adversely impacted the DAPs. Similarly, cine settings at $15 \mathrm{fps}$ when used with 'RDL+Low' notably reduced the radiation levels while other cine settings did not. There was significant dispersion of $75^{\text {th }}$ percentile of DAP between the 4 centres for all procedures ( ' $p$ ' $<0.05)$ (Figure 2). The maximal range of median DAP between centres was 7-21 Gy $\cdot \mathrm{cm}^{2}, 13-52 \mathrm{~Gy} \cdot \mathrm{cm}^{2}$, and $20-57 \mathrm{~Gy} \cdot \mathrm{cm}^{2}$ for CAG, PCI and CAG+PCI respectively. Institution 4 had the lowest DAP median

Table 1. Procedure distribution, demographic profile, cardiovascular risk factors and indications for procedure.

\begin{tabular}{|c|c|c|c|c|}
\hline & All procedures & CAG & PCI & CAG+PCI \\
\hline Number & 4371 & 2906 & 750 & 715 \\
\hline Institution 1 (\%) & 835 (19) & $546(19)$ & $76(10)$ & $213(30)$ \\
\hline Institution 2 (\%) & $982(22)$ & $513(18)$ & $95(13)$ & $374(52)$ \\
\hline Institution 3 (\%) & $1147(26)$ & $778(27)$ & $274(37)$ & $95(13)$ \\
\hline Institution 4 (\%) & 1407 (32) & $1070(37)$ & $304(41)$ & $33(5)$ \\
\hline Age (mean, SD) years & $57.7 \pm 10.7$ & $57.4 \pm 10.7$ & $58.0 \pm 10.6$ & $58.5 \pm 11.0$ \\
\hline Male (\%) & $3247(71)$ & $2073(71)$ & $572(76)$ & $602(84)$ \\
\hline Diabetes (\%) & 1795 (39) & $1186(41)$ & $298(40)$ & $311(43)$ \\
\hline Hypertension (\%) & $1951(42)$ & $1318(45)$ & $310(41)$ & $323(45)$ \\
\hline $\mathrm{BMI}^{*}$ (mean, SD) kg/m² & $26.0 \pm 4.2$ & $26.3 \pm 4.3$ & $26.1 \pm 4.1$ & $25.1 \pm 3.5$ \\
\hline $\begin{array}{l}\mathrm{BMI}^{*}<25(\%) \\
\mathrm{BMI}^{*} \geq 25 \text { to }<30(\%) \\
\mathrm{BMI}^{*} \geq 30(\%)\end{array}$ & $\begin{array}{r}1923(44) \\
1699(39) \\
705(16)\end{array}$ & $\begin{array}{r}1207(42) \\
1148(40) \\
536(19)\end{array}$ & $\begin{array}{l}316(43) \\
311(42) \\
108(15)\end{array}$ & $\begin{array}{c}400(57) \\
240(34) \\
63(9)\end{array}$ \\
\hline Prior PCl (\%) & $238(5)$ & $129(4)$ & $51(7)$ & $58(8)$ \\
\hline Prior CABG (\%) & $89(2)$ & $60(2)$ & $15(2)$ & $14(2)$ \\
\hline STEMI (\%) & $353(8)$ & $140(5)$ & $18(2)$ & $195(27)$ \\
\hline NSTEMI/unstable angina (\%) & $840(18)$ & $513(18)$ & $71(9)$ & $256(36)$ \\
\hline Elective (\%) & 3177 (69) & $2256(78)$ & $658(88)$ & $263(37)$ \\
\hline
\end{tabular}




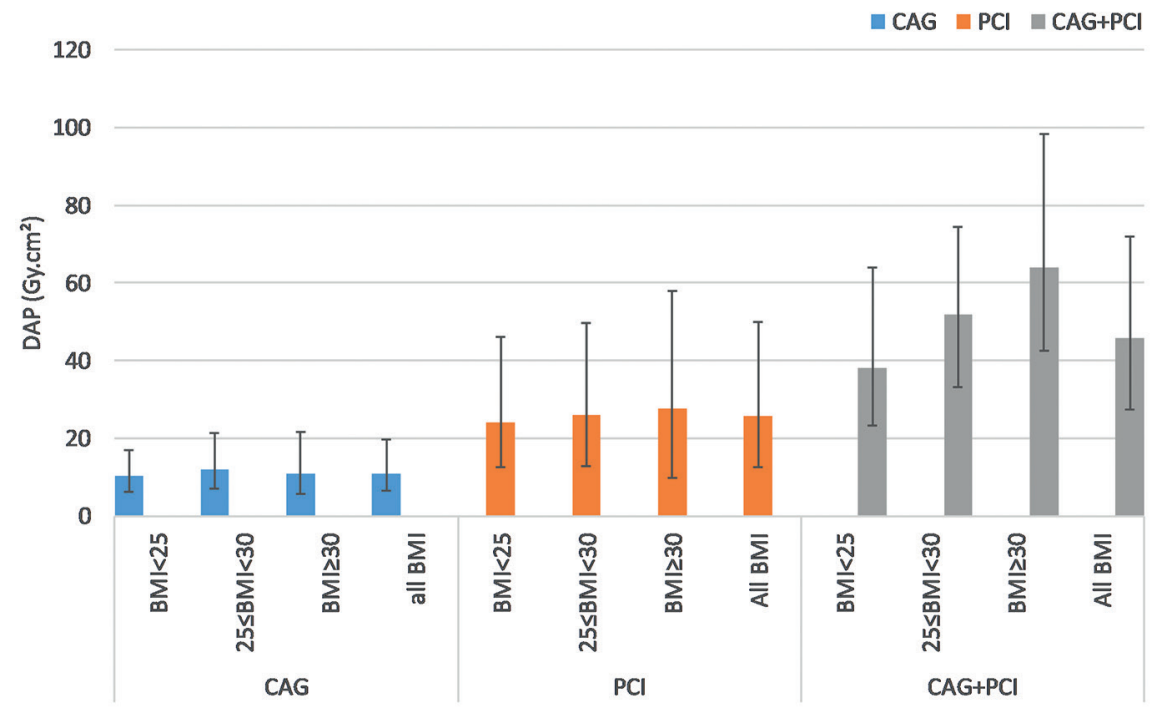

Figure 1. Impact of BMI on patient radiation dose. BMI: body mass index, DAP: dose area product

Table 2. Procedural data.

\begin{tabular}{|l|c|}
\hline ACCESS ROUTES* & N (\%) \\
\hline Radial (\%) & $3312(76.0)$ \\
\hline Femoral (\%) & $991(22.8)$ \\
\hline Bi femoral (\%) & $15(0.3)$ \\
\hline Radial+Femoral (\%) & $38(0.4)$ \\
\hline PROCEDURE TYPE & $2906(63.2)$ \\
\hline CAG (\%) & $750(16.3)$ \\
\hline PCI (\%) & $715(15.5)$ \\
\hline CAG+PCI (\%) & $1.2 \pm 0.4$ \\
\hline No of vessels treated (mean, SD) & $1.3 \pm 0.6$ \\
\hline No of stents implanted (mean, SD) & $51 \pm 9$ \\
\hline AMOUNT OF CONTRAST MEDIA USED & $150 \pm 18$ \\
\hline CAG (mean, SD) ml & $146 \pm 35$ \\
\hline PCI (mean, SD) ml & $11(0.3)$ \\
\hline CAG+PCI (mean, SD) mI & $4(0.1)$ \\
\hline ADJUNCTIVE TECHNOLOGIES USED & $5(0.2)$ \\
\hline Rotablator (\%) & $17(0.4)$ \\
\hline OCT (\%) & $17(0.5)$ \\
\hline FFR (\%) & $25(0.7)$ \\
\hline IVUS (\%) & $34(1.0)$ \\
\hline IABP (\%) & $6(0.2)$ \\
\hline PROCEDURE COMPLICATION & \\
\hline Dissection (\%) & \\
\hline Unsuccessful procedure (\%) & \\
\hline Thrombosis (\%) & \\
\hline Occlusion (\%) & \\
\hline *Information missing regarding access route for 15 procedures. \\
CAG: coronary angiography; FFR: fractional flow reserve; \\
IABP: intra-aortic balloon pump; IVUS: intravascular ultrasound; \\
OCT: optical coherence tomography; PCI: percutaneous coronary \\
intervention
\end{tabular}

for each of the 3 groups and this was the only institution which used "7.5 frame/s RDL+Low" settings for fluoroscopy.

Distribution of CAK is depicted in Figure 3. Overall, 87.4\% of the procedures were below $1 \mathrm{~Gy}$, including $98 \%$ of $\mathrm{CAG}, 74 \%$ of PCI and $57 \%$ of CAG+PCI. $98.8 \%$ of the procedures were below the first notification threshold of $3 \mathrm{~Gy} .1 \%$ of the examinations attained a radiation dose between 3 and 5 Gy. Only $0.3 \%$ of all PCIs (6 elective and 6 ad hoc) exceeded the substantial radiation dose level of $5 \mathrm{~Gy}$, above which patient follow-up is recommended ${ }^{2}$. This category was inclusive of 3 patients with complex primary PCI, 4 PCIs for calcified lesions, 1 complex bifurcation PCI, 3 PCIs for chronic total occlusion, and 1 patient who had PCI-related complications. However, lesion complexity data was not included in the study analysis as it was not available for all patients. Comparison of radiation data from the current study with international references and recent literature are shown in Figure $\mathbf{4}$ as well as in Supplementary Table 2 and Supplementary Table $3^{6-16}$. For each procedure category, the study median DAP and $75^{\text {th }}$ percentile DAP were compared with data from previously published studies: 4 study datasets out of 31 had comparable or lower DAP for CAG and 9 out of 40 had similar outcomes for PCI. This trend also continued with comparisons of CAK and FT.

\section{Discussion}

The major observations of our study are firstly that DAP and CAK during diagnostic and interventional coronary procedures from a selection of Indian centres are comparable, and in the low range in reference to international standards. Secondly, only $1 \%$ of all the procedures received a dose between 3 Gy and 5 Gy and $0.3 \%$ of the examinations attained a dose above the cut-off value 5 Gy. Thirdly, there is considerable variation across the sites with regard to the radiation parameters. Fourthly, male gender, higher 
Table 3. Procedure specific radiation data.

\begin{tabular}{|c|c|c|c|c|c|}
\hline & N & Mean \pm SD & Median & $\begin{array}{c}25^{\text {th }} \\
\text { Percentile }\end{array}$ & $\begin{array}{c}75^{\text {th }} \\
\text { Percentile }\end{array}$ \\
\hline Goup I: CAG Group I & 2906 & & & & \\
\hline $\operatorname{DAP}\left(G y \cdot \mathrm{cm}^{2}\right)$ & & $15.8 \pm 16.4$ & 11.0 & 6.4 & 19.6 \\
\hline Fluoroscopy DAP (Gy.cm²) & & $4.4 \pm 8.9$ & 1.9 & 0.9 & 4.5 \\
\hline Cine DAP $\left(G y \cdot \mathrm{cm}^{2}\right)$ & & $11.5 \pm 9.7$ & 8.4 & 5.1 & 14.5 \\
\hline CAK (mGy) & & $261 \pm 255$ & 185 & 112 & 325 \\
\hline Fluoroscopy CAK (mGy) & & $63 \pm 129$ & 28 & 12 & 64 \\
\hline Cine CAK (mGy) & & $198 \pm 162$ & 150 & 91 & 251 \\
\hline Acquisition duration (min) & & $4.3 \pm 4.5$ & 2.8 & 1.7 & 5.1 \\
\hline Fluoroscopy time (min) & & $3.8 \pm 4.4$ & 2.4 & 1.3 & 4.5 \\
\hline Cine time (min) & & $0.5 \pm 0.2$ & 0.5 & 0.4 & 0.6 \\
\hline Number of cine frames & & $460 \pm 204$ & 427 & 320 & 552 \\
\hline Group II: PCI & 750 & & & & \\
\hline $\mathrm{DAP}\left(\mathrm{Gy} \cdot \mathrm{cm}^{2}\right)$ & & $40.4 \pm 47.1$ & 25.7 & 12.5 & 49.8 \\
\hline Fluoroscopy DAP (Gy.cm²) & & $20.8 \pm 29.9$ & 11.4 & 5.3 & 23.3 \\
\hline Cine DAP $\left(G y \cdot \mathrm{cm}^{2}\right)$ & & $19.5 \pm 21.0$ & 13.1 & 6.5 & 25.6 \\
\hline CAK (mGy) & & $825 \pm 941$ & 533 & 243 & 1016 \\
\hline Fluoroscopy CAK (mGy) & & $418 \pm 591$ & 229 & 98 & 488 \\
\hline Cine CAK (mGy) & & $406 \pm 423$ & 280 & 138 & 533 \\
\hline Acquisition duration (min) & & $15.1 \pm 11$ & 12.4 & 7.9 & 19.3 \\
\hline Fluoroscopy time (min) & & $14.1 \pm 10.6$ & 11.4 & 7.1 & 18.2 \\
\hline Cine time (min) & & $1.0 \pm 0.6$ & 0.8 & 0.6 & 1.3 \\
\hline Number of cine frames & & $885 \pm 551$ & 738 & 520 & 1128 \\
\hline Group III: CAG+PCI & 715 & & & & \\
\hline $\operatorname{DAP}\left(\mathrm{Gy} \cdot \mathrm{cm}^{2}\right)$ & & $56.2 \pm 42.7$ & 45.8 & 27.3 & 72.0 \\
\hline Fluoroscopy DAP (Gy.cm²) & & $25.0 \pm 26.7$ & 17.3 & 9.6 & 31.7 \\
\hline Cine DAP (Gy.cm²) & & $31.2 \pm 21.7$ & 26.9 & 15.7 & 41.5 \\
\hline CAK (mGy) & & $1135 \pm 939$ & 891 & 526 & 1461 \\
\hline Fluoroscopy CAK (mGy) & & $494 \pm 595$ & 325 & 174 & 609 \\
\hline Cine CAK (mGy) & & $641 \pm 454$ & 539 & 324 & 861 \\
\hline Acquisition duration (min) & & $13.6 \pm 9.3$ & 11.7 & 7.7 & 16.3 \\
\hline Fluoroscopy time (min) & & $12.4 \pm 9$ & 10.6 & 6.7 & 15.1 \\
\hline Cine time (min) & & $1.2 \pm 0.5$ & 1.1 & 0.8 & 1.4 \\
\hline Number of cine frames & & $1039 \pm 474$ & 962 & 729 & 1245 \\
\hline
\end{tabular}

BMI, combining $\mathrm{CAG}+\mathrm{PCI}$, fluoroscopy time, number of cine frames, and image acquisition settings were significant predictors of higher DAP.

Historically, radiation dose during catheterisation procedures varies widely based on age, BMI, radial route, previous bypass grafting, lesion complexity, equipment generation, technical settings and operator experience ${ }^{17,18}$. Gender-based patterns for radiation exposure across catheterisation laboratories are unknown. In this study, male gender is an important predictor but women were under-represented (29\%) and the significance of this finding after adjustment for lesion complexity is not analysed. However, in a study exploring mean
Table 4. Contributors to increased radiation dose.

\begin{tabular}{|c|c|c|c|c|}
\hline Variables & ' $\beta$ ' & SE & $95 \% \mathrm{CI}$ & ' $p$ '-value \\
\hline Gender: male vs female & 1.3311 & 1.04 & $(1.22-1.43)$ & $<0.001$ \\
\hline BMI $\left(\mathrm{kg} / \mathrm{m}^{2}\right)$ & 1.0300 & 1.00 & $(1.02-1.04)$ & $<0.001$ \\
\hline $\begin{array}{l}\text { Procedure type: } \mathrm{PCl} \text { vs } \\
\mathrm{CAG}+\mathrm{PCl}\end{array}$ & 0.9205 & 1.04 & $(0.95-0.99)$ & $<0.001$ \\
\hline Fluoroscopy time (min) & 1.0276 & 1.00 & $(1.02-1.03)$ & $<0.001$ \\
\hline Number of cine frames & 1.0006 & 1.00 & $(1.00-1.00)$ & $<0.001$ \\
\hline Fluoroscopy setting & & & & 0.023 \\
\hline 7.5fps RDL+Low & 0.6107 & 1.05 & $(0.56-0.67)$ & $<0.001$ \\
\hline 15fps RDL+Normal & 1.6620 & 1.11 & $(1.37-2.04)$ & $<0.001$ \\
\hline 15fps Smart IQ Low & 0.9418 & 1.15 & $(0.71-1.24)$ & 0.667 \\
\hline 15fps Smart IQ Normal & 1.3825 & 1.08 & $(1.18-1.61)$ & $<0.001$ \\
\hline Cine setting & & & & $<0.001$ \\
\hline 15fps IQ Standard Low & 0.6157 & 1.34 & $(0.35-1.34)$ & 0.096 \\
\hline 15fps RDL+Low & 0.6480 & 1.08 & $(0.56-1.08)$ & $<0.001$ \\
\hline 15fps RDL+Normal & 1.0367 & 1.13 & $(0.91-1.13)$ & 0.769 \\
\hline \multicolumn{5}{|c|}{$\begin{array}{l}\text { BMI: body mass index; CAG: coronary angiography; } \mathrm{PCI} \text { : percutaneous } \\
\text { coronary intervention. Beta coefficients }(\beta) \text { are given after } \\
\text { re-transformation [exp(beta coefficient)] to describe the relative } \\
\text { influence of each variable. }\end{array}$} \\
\hline
\end{tabular}

effective radiation dose for nuclear cardiology procedures, it was shown that women required a slightly lower radiation dose $(9.6 \pm 4.5 \mathrm{mSv})$ than men $(10.3 \pm 4.5 \mathrm{mSv}, \mathrm{p}<0.001)^{19}$. On the other hand, the adverse relationship between BMI and radiation dose is well established ${ }^{18}$. Ad hoc PCI increased DRL significantly, with mean DAP $56.2 \pm 42.7 \mathrm{~Gy} \cdot \mathrm{cm}^{2}$ where as the PCI group had a mean of $40.4 \pm 47.1 \mathrm{~Gy} \cdot \mathrm{cm}^{2}$. In a study published by Truffa et $\mathrm{al}^{20}$, the ad hoc group had lower total DAP $119.7 \pm 70.7 \mathrm{~Gy} \cdot \mathrm{cm}^{2}$, compared to the staged group, 139.2 $\pm 5.3 \mathrm{~Gy} \cdot \mathrm{cm}^{2}(\mathrm{p}<0.001)$, but the staged group's total DAP included the radiation during both CAG and PCI, and thus cannot be compared to the present study. Fluoroscopy time, number of cine frames, and image acquisition settings are conventional risk factors of radiation ${ }^{18}$.

All the hospitals participating in the study have used the same equipment for X-ray imaging but the choice of configurable settings was left to the physician's preference. At the institution which recorded the lowest mean DAP for all procedures, the physicians opted for low frame rates as well as low radiation protocols for all the procedures. Preference of image technical settings between sites to accomplish a clinical task, operator's practice and awareness of radiation reduction techniques (such as usage of collimation while limiting magnification, limitation of steep angulations, optimal placement of image receptor as close as possible to the patient, selection of lower frame rates and lower dose level preference, use of fluoro-store function instead of cine) all have an impact on the levels of radiation. Georges et $\mathrm{al}^{17}$, in their analysis of 34,436 CAGs and 28,932 PCIs across 44 centres in France, observed significant differences in the radiation doses between participating centres. The maximal range of median KAP between centres was 9-54 Gy.cm ${ }^{2}$ and 16-126 Gy. $\mathrm{cm}^{2}$ for CAG and PCI 


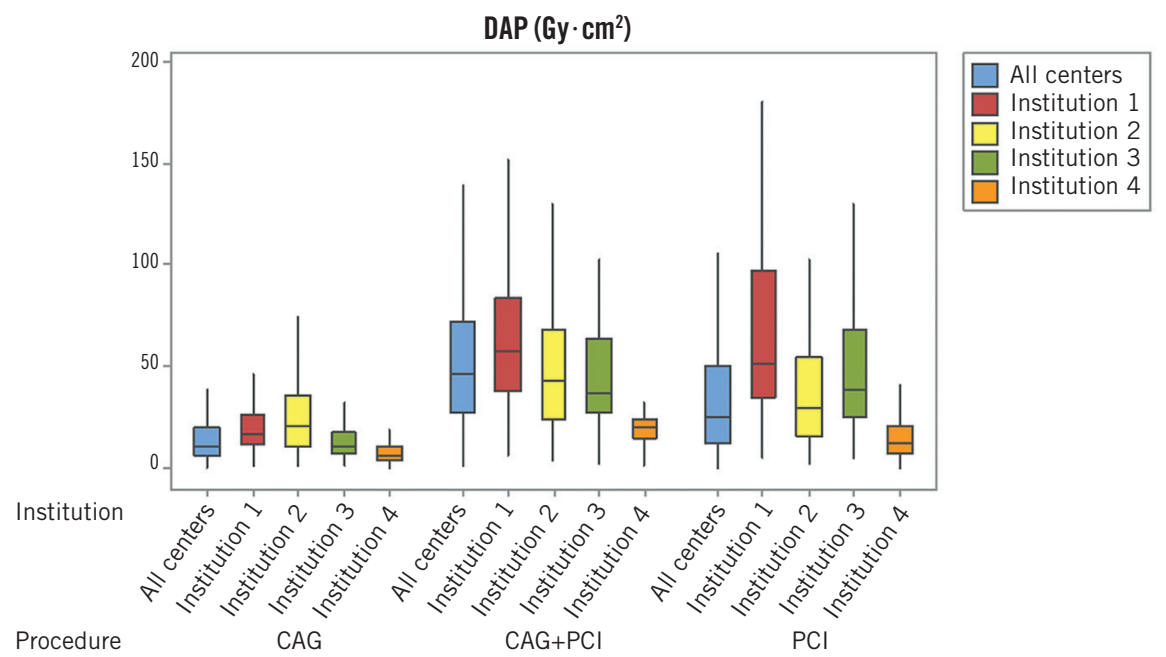

Figure 2. $75^{\text {th }}$ percentile DAP data by institutions. CAG: coronary angiography; $C A G+P C I$ : coronary angiography followed by percutaneous coronary intervention; DAP: dose area product; PCI: percutaneous coronary intervention

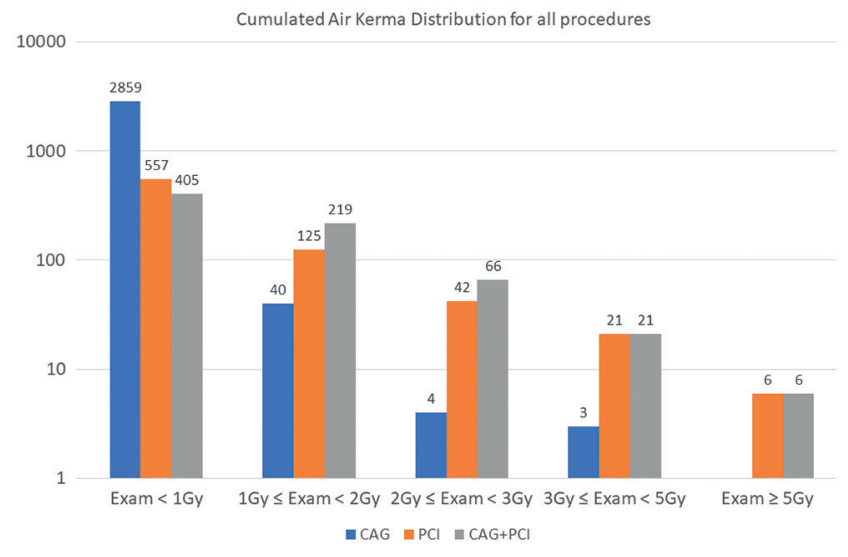

Figure 3. Cumulative air kerma distribution for all procedures, (CAG, PCI, $C A G+P C I)-L o g$ scale. CAG: coronary angiography; $C A G+P C I$ : coronary angiography followed by percutaneous coronary intervention; PCI: percutaneous coronary intervention;

respectively. When comparison was made between centres delivering lower and higher radiation doses, use of old equipment, routine left ventriculography, and use of frame rates $>7.5 \mathrm{fps}$ were more frequent in centres delivering higher doses.

The incidence of high dose exposure varies between $0.1 \%$ and $1.0 \%$ among different studies ${ }^{17}$. Historically, high radiation doses commonly occur in patients with high BMI and in those undergoing complex interventional procedures such as chronic total occlusions or treatment of calcified lesions or anomalous coronary arteries, or when procedure complications occur ${ }^{21}$. Similar findings were observed in this study and are consistent with other published studies ${ }^{17}$. None of the patients with radiation doses above 5 Gy reported skin injuries. However, the current study did not mandate follow-up of patients who received high radiation doses.

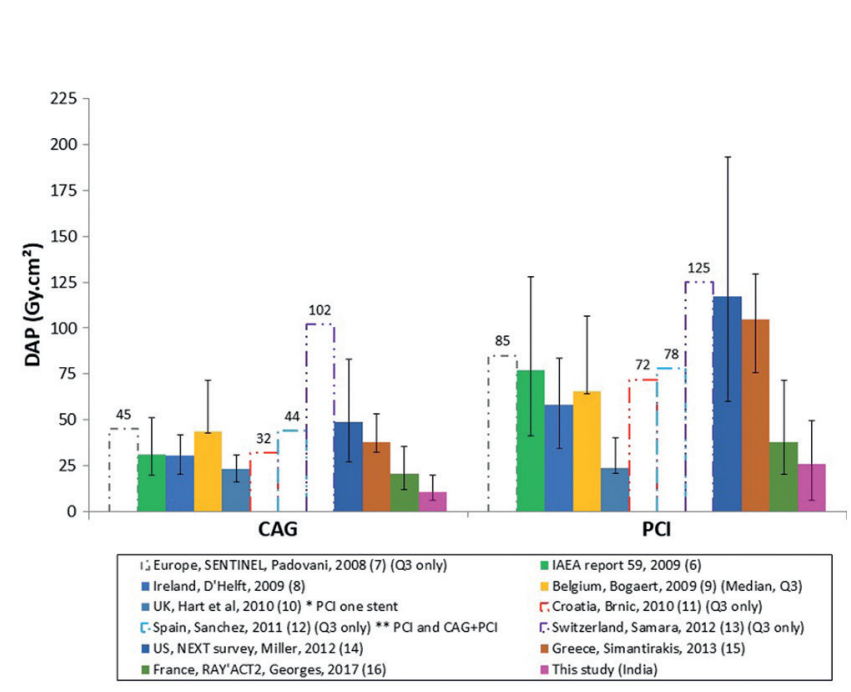

Figure 4. Cumulative DAP $\left(G y . \mathrm{cm}^{2}\right)$ in comparison with international references for CAG and PCI categories. Median and interquartile range are given, unless otherwise indicated. $C A G$ : coronary angiography; DAP: dose area product; PCI: percutaneous coronary intervention

The main objective of any radiation dose assessment is to minimise the detrimental effects of radiation by reducing exposure to it in the catheterisation laboratory. DRLs serve as a benchmark that gives an opportunity for the individual laboratories to compare their performance and to adapt policies to curtail unnecessary exposure to radiation. The DRLs from the current study were $19.6 \mathrm{~Gy} \cdot \mathrm{cm}^{2}$ for $\mathrm{CAG} ; 49.8 \mathrm{~Gy} \cdot \mathrm{cm}^{2}$ for PCI ; and $72 \mathrm{~Gy} \cdot \mathrm{cm}^{2}$ for $\mathrm{CAG}+\mathrm{PCI}$, considerably lower than the reference limits of other international studies (Supplementary Table 2 and Supplementary

Table 3 ). Various factors could have contributed to this. Indians with cardiovascular disease are known to have a lower BMI than 
other ethnicities ${ }^{22}$. Most of the reference studies were much older; hence, this study might have had the benefit of improved radiation awareness, better experience of the operators, and recent advances in technical equipment.

\section{Limitations}

The current study has some important limitations. Radiation dose measurements were restricted to the three selected procedures (CAG, PCI, CAG+PCI) and hence no reference values can be deduced from this study for other catheterisation procedures. Detailed technical factors such as field of view, collimation, source-to-image distance and angulations have not been monitored. Lesion complexity and operator experience were not considered. There is no follow-up of patients who have received high radiation doses and the adverse effects of these high doses have not been reported.

\section{Conclusions}

DRLs for diagnostic and interventional coronary angiography procedures in India were calculated in this study. Despite variations across centres, radiation doses from a selection of tertiary cardiac care centres using similar equipment are comparable and are in the low range with reference to international standards. The establishment of these DRLs can be used as a benchmark for new or similar catheterisation laboratories.

\section{Impact on daily practice}

The current study provides preliminary radiation exposure reference levels for commonly performed coronary procedures in India. This may serve as a reference for evaluation of radiation dose in individual catheterisation laboratories, to adapt policies and practices to improve their radiation doses.

\section{Acknowledgement}

The authors thank Varun Gopinathand Bhavani who provided support in this study.

\section{Funding}

This work was supported in part by a GE Healthcare grant.

\section{Conflict of interest statement}

V. Subban has received an institutional research grant from GE Healthcare. S. Amelot is a GE Healthcare employee. The other authors have no conflicts of interest to declare.

\section{References}

1. Kato M, Chida K, Sato T, Oosaka H, Tosa T, Munehisa M, Kadowaki K. The necessity of follow-up for radiation skin injuries in patients after percutaneous coronary interventions: radiation skin injuries will often be overlooked clinically. Acta radiologica. 2012; 53:1040-4.
2. Chambers CE, Fetterly KA, Holzer R, Lin PJ, Blankenship JC, Balter S, Laskey WK. Radiation safety program for the cardiac catheterization laboratory. Catheter Cardiovasc Interv. 2011;77: 546-56.

3. The 2007 Recommendations of the International Commission on Radiological Protection. ICRP publication 103. Annals of the ICRP. https://www.icrp.org/publication.asp?id=ICRP\%20 Publication\%20103

4. Khanna NN, Rao S. Growth of Interventional Cardiology in India: The Relevance of National Interventional Council (CSINIC). In: Sarat Chandra K, Bansal M, editors. Cardiology update 2017. Gurgaon, India: Elsevier; 2017. p. 211-9.

5. Hirshfeld JW Jr, Balter S, Brinker JA, Kern MJ, Klein LW, Lindsay BD, Tommaso CL, Tracy CM, Wagner LK, Creager MA, Elnicki M, Hirshfeld JW Jr, Lorell BH, Rodgers GP, Tracy CM, Weitz HH; American College of Cardiology Foundation; American Heart Association; American College of Physicians. ACCF/AHA/ HRS/SCAI clinical competence statement on physician knowledge to optimize patient safety and image quality in fluoroscopically guided invasive cardiovascular procedures. A report of the American College of Cardiology Foundation/American Heart Association/American College of Physicians Task Force on Clinical Competence and Training. J Am Coll Cardiol. 2004;44:2259-82.

6 . Establishing guidance levels in x-ray guided medical interventional procedures: a Pilot study - Vienna: International Atomic Energy Agency, 2008 - Safety reports series, ISSN 1020-6450, no. 59. 2009. https://www.iaea.org/publications/7941/establishingguidance-levels-in-x-ray-guided-medical-interventionalprocedures-a-pilot-study

7. Padovani R, Vano E, Trianni A, Bokou C, Bosmans H, Bor D, Jankowski J, Torbica P, Kepler K, Dowling A, Milu C, Tsapaki V, Salat D, Vassileva J, Faulkner K . Reference levels at European level for cardiac interventional procedures. Radiat Prot Dosimetry. 2008;129:104-7.

8. D'Helft CJ, Brennan PC, McGee AM, McFadden SL, Hughes CM, Winder JR, Rainford LA. Potential Irish dose reference levels for cardiac interventional examinations. $\mathrm{Br} J$ Radiol. 2009;82:296-302.

9. Bogaert E, Bacher K, Lemmens K, Carlier M, Desmet W, De Wagter X, Djian D, Hanet C, Heyndrickx G, Legrand V, Taeymans Y, Thierens H. A large-scale multicentre study of patient skin doses in interventional cardiology: dose-area product action levels and dose reference levels. Br J Radiol. 2009;82:303-12.

10. Hart D, Hillier MC, Wall BF. National reference doses for common radiographic, fluoroscopic and dental X-ray examinations in the UK. Br J Radiol. 2009;82:1-12.

11. Brnic Z, Krpan T, Faj D, Kubelka D, Ramac JP, Posedel D, Steiner R, Vidjak V, Brnić V, Visković K, Baraban V. Patient radiation doses in the most common interventional cardiology procedures in Croatia: first results. Radiat Prot Dosimetry. 2010; 138:180-6

12. Sanchez R, Vano E, Fernandez JM, Sotil J, Carrera F, Armas J, Rosales F, Pifarre X, Escaned J, Angel J, Diaz JF, Bosa F, Saez JR, 
Goicolea J. A national programme for patient and staff dose monitoring in interventional cardiology. Radiat Prot Dosimetry. 2011; 147:57-61.

13. Samara ET, Aroua A, De Palma R, Stauffer JC, Schmidt S, Trueb PR, Stuessi A, Treier R, Bochud F, Verdun FR.An audit of diagnostic reference levels in interventional cardiology and radiology: are there differences between academic and non-academic centres? Radiat Prot Dosimetry. 2012;148:74-82.

14. Miller DL, Hilohi CM, Spelic DC. Patient radiation doses in interventional cardiology in the U.S.: advisory data sets and possible initial values for U.S. reference levels. Med Phys. 2012;39: 6276-86.

15. Simantirakis G, Koukorava C, Kalathaki M, Pafilis C, Kaisas I, Economides S, Hourdakis CJ, Kamenopoulou V, Georgiou E. Reference levels and patient doses in interventional cardiology procedures in Greece. Eur Radiol. 2013; 23:2324-32.

16. Georges JL, Belle L, Etard C, Azowa JB, Albert F, Pansieri M, Monsegu J, Barbou F, Trouillet C, Leddet P, Livarek B, Marcaggi X, Hanssen M, Cattan S; The Ray'act-Investigators. Radiation Doses to Patients in Interventional Coronary Procedures-Estimation of Updated National Reference Levels by Dose Audit. Radiat Prot Dosimetry. 2017;175:17-25.

17. Georges JL, Belle L, Ricard C, Cattan S, Albert F, Hirsch JL, Monsegu J, Dibie A, Khalife K, Caussin C, Maccia C, Livarek B, Hanssen M; RAY'ACT investigators. Patient exposure to X-rays during coronary angiography and percutaneous transluminal coronary intervention: results of a multicenter national survey. Catheter Cardiovasc Interv. 2014;83:729-38.

18. Journy N, Sinno-Tellier S, Maccia C, Le Tertre A, Pirard P, Pagès $\mathrm{P}$, Eilstein D, Donadieu J, Bar O. Main clinical, therapeutic and technical factors related to patient's maximum skin dose in interventional cardiology procedures. Br J Radiol. 2012;85: 433-42.

19. Shi L, Dorbala S, Paez D, Shaw LJ, Zukotynski KA, Pascual TN, Karthikeyan G, Vitola JV, Better N, Bokhari N, Rehani MM, Kashyap R, Dondi M, Mercuri M, Einstein AJ; INCAPS Investigators Group. Gender Differences in Radiation Dose From Nuclear Cardiology Studies Across the World: Findings From the INCAPS Registry. JACC Cardiovasc Imaging. 2016; 9:376-84.

20. Truffa MA, Alves GM, Bernardi F, Esteves Filho A, Ribeiro E, Galon MZ, Spadaro A, Kajita LJ, Arrieta R, Lemos PA. Does Ad Hoc Coronary Intervention Reduce Radiation Exposure? - Analysis of 568 Patients. Arq Bras Cardiol. 2015;105:487-92.

21. Delewi R, Hoebers LP, Ramunddal T, Henriques JP, Angerås O, Stewart J, Robertsson L, Wahlin M, Petursson P, Piek JJ, Albertsson P, Matejka G, Omerovic E. Clinical and procedural characteristics associated with higher radiation exposure during percutaneous coronary interventions and coronary angiography. Circ Cardiovasc Interv. 2013;6:501-6.

22. Nag T, Ghosh A. Cardiovascular disease risk factors in Asian Indian population: A systematic review. J Cardiovasc Dis Res. 2013;4:222-8.
23. Abdelaal E, Plourde G, MacHaalany J, Arsenault J, Rimac G, Déry JP, Barbeau G, Larose E, De Larochellière R, Nguyen CM, Allende R, Ribeiro H, Costerousse O, Mongrain R, Bertrand OF; Interventional Cardiologists at Quebec Heart-Lung Institute. Effectiveness of low rate fluoroscopy at reducing operator and patient radiation dose during transradial coronary angiography and interventions. JACC Cardiovasc Interv. 2014;7:567-74.

24. Eloot L, Thierens H, Taeymans Y, Drieghe B, De Pooter J, Van Peteghem S, Buytaert D, Gijs T, Lapere R, Bacher K. Novel X-ray imaging technology enables significant patient dose reduction in interventional cardiology while maintaining diagnostic image quality. Catheter Cardiovasc Interv. 2015;86:E205-12.

25. Bracken JA, Mauti M, Kim MS, Messenger JC, Carroll JD. A Radiation Dose Reduction Technology to Improve Patient Safety During Cardiac Catheterization Interventions. J Interv Cardiol. 2015;28:493-7.

26. Livingstone RS, Chase D, Varghese A, George PV, George OK. Transition from image intensifier to flat panel detector in interventional cardiology: Impact of radiation dose. J Med Phys. 2015;40: 24-8.

27. Nakamura S, Kobayashi T, Funatsu A, Okada T, Mauti M, Waizumi Y, Yamada S. Patient radiation dose reduction using an $\mathrm{X}$-ray imaging noise reduction technology for cardiac angiography and intervention. Heart Vessels. 2016;31:655-63.

28. Varghese A, Livingstone RS, Varghese L, Kumar P, Srinath SC, George OK, George PV. Radiation doses and estimated risk from angiographic projections during coronary angiography performed using novel flat detector. J Appl Clin Med Phys. 2016; 17:433-41.

29. Ryckx N, Goy JJ, Stauffer JC, Verdun FR. Patient Dose Assessment after Interventional Cardiology Procedures: A MultiCentric Approach to Trigger Optimisation. Radiat Prot Dosimetry. 2016;169:249-52.

30. Didier R, Magalhaes MA, Koifman E, Leven F, Castellant P, Boschat J, Jobic Y, Kiramijyan S, Nicol PP, Gilard M. The utilisation of the cardiovascular automated radiation reduction X-ray system (CARS) in the cardiac catheterisation laboratory aids in the reduction of the patient radiation dose. EuroIntervention. 2016; 12:e948-56.

31. Hansen JW, Foy A, Schmidt T, Ghahramani M, Chambers CE. Fluoroscopy pulse rate reduction during diagnostic and therapeutic imaging in the cardiac catheterization laboratory: An evaluation of radiation dose, procedure complications and outcomes. Catheter Cardiovasc Interv. 2017; 89:665-70.

32. Jurado-Roman A, Sanchez-Perez I, Lozano Ruiz-Poveda F, López-Lluva MT, Pinilla-Echeverri N, Moreno Arciniegas A, Agudo-Quilez P, Gil Agudo A. Effectiveness of the implementation of a simple radiation reduction protocol in the catheterization laboratory. Cardiovasc Revasc Med. 2016;17:328-32.

33. Wilson SM, Prasan AM, Virdi A, Lassere M, Ison G, Ramsay DR, Weaver JC. Real-time colour pictorial radiation monitoring during coronary angiography: effect on patient peak skin and total dose during coronary angiography. EuroIntervention. 2016;12: e939-47. 
34. Kastrati M, Langenbrink L, Piatkowski M, Michaelsen J, Reimann D, Hoffmann R. Reducing Radiation Dose in Coronary Angiography and Angioplasty Using Image Noise Reduction Technology. Am J Cardiol. 2016;118:353-6.

35. Tarighatnia A, Mohammad Alian AH, Ghojazadeh M, Farajollahi AR. Comparison of the patient radiation exposure during coronary angiography and angioplasty procedures using transradial and trans-femoral access. $J$ Cardiovasc Thorac Res. 2016;8:77-82.

36. Sinha SK, Mishra V, Afdaali N, Jha MJ, Kumar A, Asif M, Thakur R, and Varma CM. Coronary Angiography Safety between Transradial and Transfemoral Access. Cardiol Res Pract. 2016;2016:4013843. Retracted: Cardiol Res Pract. 2018;2018: 3045963.

37. Uniyal SC, Chaturvedi V, Sharma SD, Rawat A. Patient Dosimetry during Interventional Cardiac Procedures in a Dedicated Catheterization Laboratory. Radiat Prot Dosimetry. 2017;175:201-8. 38. Balter S, Brinkman M, Kalra S, Nazif T, Parikh M, Kirtane AJ, Moses J, Leon M, Feri A, Green P, Ali ZA, Liao M, Karmpaliotis D. Novel radiation dose reduction fluoroscopic technology facilitates chronic total occlusion percutaneous coronary interventions. EuroIntervention. 2017:13:e1468-74.

39. Ordiales JM, Vano E, Nogales JM, Ramos J, López-Mínguez JR, Martínez G, Cerrato P, Álvarez FJ. Optimisation of imaging protocols in interventional cardiology: impact on patient doses. $J$ Radiol Prot. 2017;37:684-96.

40. Gunja A, Pandey Y, Xie H, Wolska BM, Shroff AR, Ardati AK, Vidovich MI. Image noise reduction technology reduces radiation in a radial-first cardiac catheterization laboratory. Cardiovasc Revasc Med. 2017;18:197-201.

41. Faroux L, Blanpain T, Nazeyrollas P, Tassan-Mangina S, Herce B, Tourneux C, Metz D. Minimizing exposure to radiation in invasive cardiology using modern dose-reduction technology: evaluation of the real-life effects. Catheter Cardiovasc Interv. 2018;91:1194-9.

42. Sciahbasi A, Ferrante G, Fischetti D, Miklin DJ, Sarandrea A, Schirripa V, Guarracini F, Arya A, Loreni G, Bruni A, Rigattieri S, Marini M, Vagnarelli S, Scevola G, Reimers B, Hindricks G,
Cohen M. Radiation dose among different cardiac and vascular invasive procedures: The RODEO study. Int J Cardiol. 2017; 240:92-96.

43. Ichimoto E, Kadohira T, Nakayama T, De Gregorio J. Efficacy of radiation dose reduction due to real-time monitoring and visualization of peak skin dose during coronary angiography and percutaneous coronary intervention. Catheter Cardiovasc Interv. 2017; 91:717-22.

44. Boland JE, Wang LW, Love BJ, Christofi M, Muller DW. Impact of New-generation Hybrid Imaging Technology on Radiation Dose during Percutaneous Coronary Interventions and Trans-femoral Aortic Valve Implantations: A comparison with conventional flat-plate angiography. Heart Lung Circ. 2016;25: 668-75.

45. Chon MK, Chun KJ, Lee DS, Lee SY, Hwang J, Lee SH, Hwang KW, Kim JS, Park YH, Kim JH. Radiation reduction during percutaneous coronary intervention : A new protocol with a low frame rate and selective fluoroscopic image storage. Medicine (Baltimore). 2017;96:e7517.

46. Faroux L, Blanpain T, Nazeyrollas P, Tassan-Mangina S, Herce B, Tourneux C, Metz D. Trends in Patient Exposure to Radiation in Percutaneous Coronary Interventions Over a 10-Year Period. Am J Cardiol. 2017;120:927-30.

47. Gislason-Lee AJ, Keeble C, Egleston D, Bexon J, Kengyelics SM, Davies AG. Comprehensive assessment of patient image quality and radiation dose in latest generation cardiac x-ray equipment for percutaneous coronary interventions. J Med Imaging (Bellingham). 2017;4:025501.

\section{Supplementary data}

Supplementary Table 1. Site equipment and preferred acquisition protocol configurations.

Supplementary Table 2. Comparison with international references. Supplementary Table 3. Comparison with recent literature data.

The supplementary data are published online at: www.asiaintervention.org 


\section{Supplementary data}

Supplementary Table 1.Site equipment and preferred acquisition protocol configurations.

\begin{tabular}{|c|c|c|c|c|}
\hline \multirow[t]{2}{*}{ Institutions } & \multirow[t]{2}{*}{ Equipment } & \multirow[t]{2}{*}{ Installed } & \multicolumn{2}{|c|}{ Acquisition protocol configurations } \\
\hline & & & Fluoroscopy & Cine angiography \\
\hline \multirow{2}{*}{1} & Innova 2100-IQ & 2011 & 15 frames/s RDL+ Normal & 15 frames/s RDL+ Normal \\
\hline & Innova 2100-IQ & 2012 & 15 frames/s RDL+ Normal & 15 frames/s RDL+ Normal \\
\hline 2 & Innova IGS 520 & 2015 & $\begin{array}{l}\text { - Low dose protocol: } 15 \text { frames/s } \\
\text { RDL+ Low } \\
\text { - Improved image quality } \\
\text { protocol: } 15 \text { frames/s Smart IQ } \\
\text { Normal }\end{array}$ & $\begin{array}{l}\text { - Low dose protocol: } 15 \text { frames/s } \\
\text { RDL+ Low } \\
\text { - Improved image quality } \\
\text { protocol: } 15 \text { frames/s IQ } \\
\text { standard Normal }\end{array}$ \\
\hline 3 & Innova IGS 520 & 2012 & 15 frames/s RDL+ Low & 15 frames/s RDL+ Low \\
\hline 4 & Innova IGS 520 & 2013 & 7.5 frames/s RDL+ Low & 15 frames/s RDL+ Low \\
\hline
\end{tabular}

RDL: radiation dose limit 


\section{Supplementary Table 2. Comparison with international references.}

\begin{tabular}{|c|c|c|c|c|c|c|c|c|c|c|c|c|}
\hline Reference & Year & $\mathbf{N}$ & $\begin{array}{c}\text { BMI } \\
\left(\mathrm{kg} / \mathrm{m}^{2}\right)\end{array}$ & $\begin{array}{l}\text { Total DAP } \\
(\text { Gy.cm²) }\end{array}$ & P-Value & $\begin{array}{l}\text { CAK } \\
(\mathbf{m G y})\end{array}$ & P-Value & $\begin{array}{c}\text { FT } \\
(\min )\end{array}$ & P-Value & Number of exp. frames & P-Value & Site/country \\
\hline \multicolumn{13}{|l|}{ CAG } \\
\hline $\begin{array}{l}\text { This Study - } \\
\text { CAG }\end{array}$ & 2017 & 2906 & $26.3 \pm 4.3$ & $10.9(6.4-19.6)$ & - & $185(112-325)$ & - & $2.4(1.3-4.5)$ & & $427(320-552)$ & - & 4 hospitals, India \\
\hline $\begin{array}{l}\text { Europe } \\
\text { (SENTINEL) (7) }\end{array}$ & 2008 & 672 & na & $45^{\mathrm{d}}$ & - & na & - & $6.5^{\mathrm{d}}$ & & $700^{\mathrm{d}}$ & - & 9 centres, Europe \\
\hline IAEA (6) & 2009 & 2265 & $\begin{array}{l}\text { Height }(\mathrm{m}): 1.68^{\mathrm{a}} \\
\text { Weight }(\mathrm{kg}): 78.5^{\mathrm{a}}\end{array}$ & $31.8(20.8-49.4)$ & $<0.001$ & $700(500-1000)$ & $<0.001$ & $5(3-9)$ & $<0.001$ & $810(655-1003)$ & $<0.001$ & 7 centres \\
\hline Ireland (8) & 2009 & 967 & na & $30.6(20.2-41.7)$ & $<0.001$ & na & - & na & - & na & - & 14 hospitals, Ireland \\
\hline Belgium (9) & 2009 & 200 & $27^{\mathrm{a}}(19-49)^{\mathrm{c}}$ & $43.8($ na-71.3) & $<0.001$ & na & - & na & - & na & - & 8 hospitals, Belgium \\
\hline UK (10) & 2009 & na & $\begin{array}{l}\text { Weight }(\mathrm{kg}): 75- \\
85^{\mathrm{c}}\end{array}$ & $29^{\mathrm{e}}$ & - & na & - & $4.5^{\mathrm{e}}$ & - & na & - & 110 centres, UK \\
\hline Croatia (11) & 2010 & 138 & $28.2(18.6-37.2)$ & $25.3^{a}(n a-32)$ & $<0.001$ & na & - & $5.5^{\mathrm{a}}$ (na-6.6) & $<0.001$ & $554^{\mathrm{a}}(\mathrm{na}-610)$ & $<0.001$ & 4 centres, Croatia \\
\hline Spain (12) & 2011 & na & na & $44^{\mathrm{d}}$ & - & na & - & $8.0^{\mathrm{d}}$ & - & $869^{\mathrm{d}}$ & - & 6 hospitals, Spain \\
\hline $\begin{array}{l}\text { Switzerland } \\
(13)^{*}\end{array}$ & 2012 & 311 & na & $87^{a}($ na-102) & $<0.001$ & na & - & $3.2^{\mathrm{a}}(\mathrm{na}-10)$ & 1.000 & $1039^{\mathrm{a}}(\mathrm{na}-1549)$ & $<0.001$ & 23 centres, Switzerland \\
\hline $\begin{array}{lr}\text { United } & \text { States } \\
\text { (NEXT } & \text { Survey) } \\
(14) & \end{array}$ & 2012 & 1326 & na & $46.2(27.0-83.0)$ & $<0.001$ & $680(440-1180)$ & $<0.001$ & $2.7(1.8-5.4)$ & $<0.001$ & na & - & United States \\
\hline Greece (15) & 2013 & 2572 & na & $37.9(32.5-53.3)$ & $<0.001$ & na & na & $5.4(4.1-5.7)$ & $<0.001$ & na & - & 26 centres, Greece \\
\hline $\begin{array}{l}\text { France, } \\
\text { RAY'ACT-2 (16) }\end{array}$ & 2016 & 51229 & $26.8(24.2-30.1)$ & $20.8(11.8-35.7)$ & $<0.001$ & $294(164-498)$ & $<0.001$ & $3.3(2.1-5.7)$ & $<0.001$ & $404(284-566)$ & 1.000 & 61 centres, France \\
\hline \multicolumn{13}{|l|}{ PCI } \\
\hline This Study - PCI & 2017 & 750 & $26.0 \pm 4.1$ & $25.7(12.5-49.8)$ & - & $533(243-1020)$ & - & $11.4(7.1-18.2)$ & - & $738(520-1128)$ & - & 4 hospitals, India \\
\hline $\begin{array}{l}\text { Europe } \\
\text { (SENTINEL) (7) }\end{array}$ & 2008 & 662 & na & $85^{\mathrm{d}}$ & - & na & - & $15.5^{\mathrm{d}}$ & - & $1000^{\mathrm{d}}$ & - & 9 centres, Europe \\
\hline
\end{tabular}




\begin{tabular}{|c|c|c|c|c|c|c|c|c|c|c|c|c|}
\hline IAEA (6) & 2009 & 1027 & $\begin{array}{l}\text { Height }(\mathrm{m}): 1.68^{\mathrm{a}} \text {; } \\
\text { Weight }(\mathrm{kg}): 77.4^{\mathrm{a}}\end{array}$ & $53.3(29.9-98.4)$ & $<0.001$ & $1900(1100-3000)$ & $<0.001$ & $12(7-20)$ & 0.0772 & $881(527-1465)$ & $<0.001$ & \\
\hline Ireland (8) & 2009 & 463 & na & $58.1(34.3-83.6)$ & $<0.001$ & na & - & na & - & na & - & 14 hospitals, Ireland \\
\hline Belgium (9) & 2009 & 118 & $28^{\mathrm{a}}(20-47)^{\mathrm{c}}$ & 65.4 (na-106.6) & $<0.001$ & na & - & na & - & na & - & 8 hospitals, Belgium \\
\hline UK $(10)^{* * *}$ & 2009 & na & Weight: $75-85^{\circ} \mathrm{kg}$ & $50^{\mathrm{e}}$ & - & na & - & $13.0^{\mathrm{e}}$ & - & na & - & 28 centres, UK \\
\hline Croatia (11) & 2010 & 151 & $28.4(18.6-38.9)$ & $55.2^{\mathrm{a}}($ na- -72$)$ & $<0.001$ & na & - & $15.5^{\mathrm{a}}(\mathrm{na}-19)$ & $<0.001$ & 1067 (na-1270) & $<0.001$ & 4 centres, Croatia \\
\hline Spain $(12)^{* * *}$ & 2011 & na & na & $78^{\mathrm{d}}$ & - & na & - & $22.0^{\mathrm{d}}$ & - & $1762^{d}$ & - & 6 hospitals, Spain \\
\hline Switzerland (13) & 2012 & 119 & na & $91^{a}($ na-125) & $<0.001$ & na & - & $14^{\mathrm{a}}$ (na-19) & 0.584 & $1277^{\mathrm{a}}(\mathrm{na}-1837)$ & $<0.001$ & 23 centres, Switzerland \\
\hline $\begin{array}{lr}\text { United } & \text { States } \\
\text { (NEXT } & \text { Survey) } \\
(14) & \end{array}$ & 2012 & 144 & na & $99.3(60.0-193.0)$ & $<0.001$ & $1610(1000-3120)$ & $<0.001$ & $10.1(6.8-18.5)$ & 1.000 & na & - & United States \\
\hline Greece (15) & 2013 & 1899 & na & $104.7(75.8-129.3)$ & $<0.001$ & na & - & $13.8(11.0-17.8)$ & $<0.001$ & na & - & 25 centres, Greece \\
\hline $\begin{array}{l}\text { France, } \\
\text { RAY'ACT-2 (16) }\end{array}$ & 2016 & 6743 & $26.8(24.2-30.1)$ & $38.0(20.3-71.4)$ & $<0.001$ & $668(351-1285)$ & $<0.001$ & $9.8(5.7-16.8)$ & 1.000 & 537 (339-788) & 1.000 & 61 centres, France \\
\hline \multicolumn{13}{|l|}{ CAG +PCI } \\
\hline $\begin{array}{l}\text { This Study - } \\
\text { CAG+PCI }\end{array}$ & 2017 & 715 & $25.1 \pm 3.5$ & $45.8(27.3-72.0)$ & - & $891(526-1461)$ & - & $10.6(6.7-15.1)$ & - & $962(729-1245)$ & - & 4 hospitals, India \\
\hline IAEA (6) & 2009 & 817 & $\begin{array}{l}\text { Height }(\mathrm{m}): 1.69^{\mathrm{a}} \text {; } \\
\text { Weight }(\mathrm{kg}): 82.3^{\mathrm{a}}\end{array}$ & $92.9(59.1-138.3)$ & $<0.001$ & $1900(1300-2700)$ & $<0.001$ & $15(10-24)$ & $<0.001$ & $1468(1174-1976)$ & $<0.001$ & 7 centres \\
\hline Ireland (8) & 2009 & 134 & na & $77.1(50.2-106.7)$ & $<0.001$ & na & - & na & - & na & - & 14 hospitals, Ireland \\
\hline $\begin{array}{lr}\text { United } & \text { States } \\
\text { (NEXT } & \text { Survey) } \\
(14) & \end{array}$ & 2012 & 528 & na & $111.8(73.0-199.0)$ & $<0.001$ & $1780(1200-3000)$ & $<0.001$ & $10.8(7.3-18.1)$ & 0.1309 & na & - & United States \\
\hline $\begin{array}{l}\text { France, } \\
\text { RAY'ACT-2 (16) }\end{array}$ & 2016 & 35479 & $26.8(24.2-30.1)$ & $46.4(26.9-78.7)$ & 0.3268 & 757 (433-1285) & 1.000 & $9.8(6.4-15.2)$ & 0.9989 & $710(501-991)$ & 1.000 & 61 centres, France \\
\hline
\end{tabular}

Note. Radiation data values are given as median (IQR) and BMI as mean ${ }_{ \pm}$standard deviation; unless otherwise indicated.

CAK: cumulative air kerma.s; DAP: dose area product; FT fluoroscopy time

${ }^{\mathrm{a}}$ Mean; ${ }^{\mathrm{c}}$ Range; ${ }^{\mathrm{d}}$ Dose Reference Level (based on 75th Percentile); ${ }^{\mathrm{e}} 75$ th percentile of means of the rooms; na: not available; * Data normalized to average size patient (height $1.70 \mathrm{~m}$ and weight $70 \mathrm{~kg}$ ); **Single stent PCI; *** PCI and CAG+PCI combined

p-value from non-parametric 1 sample sign test when referenced data provided as median and 1 sample t test when referenced data provided as mean. 


\section{Supplementary Table 3. Comparison with recent literature data.}

\begin{tabular}{|c|c|c|c|c|c|c|c|c|c|c|c|c|c|}
\hline Author & Year & $\mathbf{N}$ & $\begin{array}{c}\text { BMI } \\
\left(\mathbf{k g} / \mathbf{m}^{2}\right)\end{array}$ & Total DAP $\left(\mathbf{G y} . \mathrm{cm}^{2}\right)$ & P-Value & $\begin{array}{c}\text { CAK } \\
(\mathbf{m G y})\end{array}$ & P-Value & $\begin{array}{c}\text { FT } \\
(\mathrm{min})\end{array}$ & P-Value & $\begin{array}{l}\text { Number of exp. } \\
\text { frames }\end{array}$ & P-Value & Site/country & Details \\
\hline \multicolumn{14}{|l|}{ CAG } \\
\hline This Study - CAG & 2017 & 2906 & $26.3 \pm 4.3$ & $10.9(6.4-19.6)$ & - & $185(112-325)$ & - & $2.4(1.3-4.5)$ & - & $427(320-552)$ & - & India (4 sites) & \\
\hline Abdelaal (23) & 2014 & 89 & $28.6 \pm 5.6$ & $23(15-31)$ & $<0.001$ & na & - & $2.6(1.8-4.5)$ & $<0.001$ & & - & Canada & $\begin{array}{l}\text { 1.Transradial access } \\
\text { 2.Reduced Fluoro framerate } \\
\text { group ( } 7.5 \mathrm{fps})\end{array}$ \\
\hline Eloot (24) & 2015 & 35 & $26.1(23.8-31.0)$ & $8.8(6.33-17.6)$ & 1.000 & na & - & $2.9(1.9-5.0)$ & $<0.001$ & na & - & Belgium & Novel Imaging system \\
\hline Bracken (25) & 2015 & 88 & $26.8(22.8-32.3)$ & $20.1(12.3-36.5)$ & $<0.001$ & $197(124-360)$ & $<0.001$ & $5.5(3.7-9.2)$ & $<0.001$ & $517(337-657)$ & $<0.001$ & USA & Dose reduction technology \\
\hline Livingstone (26) & 2015 & 222 & na & $24.4 \pm 14.5$ & $<0.001$ & na & - & $3.9^{\mathrm{a}}(0.5-10.4)^{\mathrm{c}}$ & 0.143 & na & - & India & Flat panel detector \\
\hline Nakamura (27) & 2015 & 307 & $23.2 \pm 3.7$ & $52.0($ na-80.4) & $<0.001$ & na & - & $9.9($ na -18.7$)$ & $<0.001$ & 2510 (na-3378.5) & $<0.001$ & Japan & Upgraded Imaging system \\
\hline Varghese (28) & 2016 & 140 & $25^{\mathrm{a}}$ & $14.0^{\mathrm{a}}(4.0-37.6)^{\mathrm{c}}$ & 1.000 & $231^{a}(74-622)^{c}$ & 1.000 & $3.2^{\mathrm{a}}(0.5-10.5)^{\mathrm{c}}$ & 1.000 & $525^{\mathrm{a}}(246-1063)^{\mathrm{c}}$ & $<0.001$ & India & Novel imaging system \\
\hline Ryckx (29) & 2016 & 877 & na & na (na-69) & na & na (na-41) & - & na (na-8.9) & - & na & - & Switzerland & \\
\hline Didier (30) & 2016 & 598 & $26.8 \pm 5.0$ & $27.1(16.7-41.6)$ & $<0.001$ & $336(207-507)$ & $<0.001$ & na & - & na & - & France & $\begin{array}{l}\text { Cardiovascular automated } \\
\text { reduction x-ray system }\end{array}$ \\
\hline Hansen (31) & 2016 & 130 & $\begin{array}{ll}\text { Height } & (\mathrm{m}): \\
1.69^{\mathrm{a}} & \\
& \\
\text { Weight } & (\mathrm{kg}) \text { : } \\
64.7^{\mathrm{a}} & \end{array}$ & $44.0(28.6-69.6)$ & $<0.001$ & $621(405-909)$ & $<0.001$ & $8.5^{\mathrm{a}}$ & $<0.001$ & na & - & USA & $\begin{array}{l}\text { Reduced Fluoro framerate } \\
\text { group ( } 7.5 \mathrm{fps})\end{array}$ \\
\hline Jurado-Roman (32) & 2016 & 558 & $28.6 \pm 5.7$ & $43.3 \pm 40.1$ & $<0.001$ & na & - & $8.0 \pm 7.0$ & $<0.001$ & na & - & Spain & Radiation Reduction Protocol \\
\hline Wilson (33) & 2016 & 617 & $27.6 \pm 6.0$ & $50.4 \pm 37.0$ & $<0.001$ & $440 \pm 376$ & $<0.001$ & $3.3 \pm 3.0$ & 1.000 & na & - & Australia & \\
\hline Kastrati (34) & 2016 & 397 & $28.8 \pm 5.0$ & $9.8 \pm 9.8$ & 1.000 & na & - & $4.7 \pm 4.4$ & $<0.001$ & na & - & Germany & $\begin{array}{l}\text { Cohort Noise Reduction } \\
\text { technology }\end{array}$ \\
\hline Tarighatnia (35) & 2016 & 37 & na & $17.3^{\mathrm{a}}(6.3-36.6)^{\mathrm{c}}$ & $<0.001$ & $234^{\mathrm{a}}(75-526)^{\mathrm{c}}$ & 1.000 & $3.3^{\mathrm{a}}(0.8-9.5)^{\mathrm{c}}$ & 1.000 & na & - & Iran & Transradial access \\
\hline Tarighatnia (35) & 2016 & 37 & na & $19.5^{\mathrm{a}}(6.8-107.8)^{\mathrm{c}}$ & $<0.001$ & $211^{\mathrm{a}}(87-433)^{\mathrm{c}}$ & 1.000 & $1.8^{\mathrm{a}}(0.5-8.4)^{\mathrm{c}}$ & 1.000 & na & - & Iran & Transfemoral access \\
\hline Sinha (36) & 2016 & 921 & $23.8 \pm 3.6$ & $22.3 \pm 3.46$ & $<0.001$ & na & - & $2.8 \pm 1.3$ & 1.000 & na & - & India & Transfemoral access \\
\hline
\end{tabular}




\begin{tabular}{|c|c|c|c|c|c|c|c|c|c|c|c|c|c|}
\hline Author & Year & $\mathbf{N}$ & $\begin{array}{c}\text { BMI } \\
\left(\mathbf{k g} / \mathbf{m}^{2}\right)\end{array}$ & Total DAP $\left(\mathbf{G y} . \mathbf{c m}^{2}\right)$ & P-Value & $\begin{array}{l}\text { CAK } \\
(\mathbf{m G y})\end{array}$ & P-Value & $\begin{array}{c}\text { FT } \\
(\min )\end{array}$ & P-Value & $\begin{array}{l}\text { Number of exp. } \\
\text { frames }\end{array}$ & P-Value & Site/country & Details \\
\hline Sinha (36) & 2016 & 1076 & $24.9 \pm 2.8$ & $24.2 \pm 4.21$ & $<0.001$ & na & - & $2.5 \pm 1.2$ & 1.000 & na & - & India & Transradial access \\
\hline Uniyal (37) & 2017 & 40 & $\begin{array}{l}\text { Weight: } 74 \pm 9.5 \\
\mathrm{~kg}\end{array}$ & $21.1 \pm 19.8$ & $<0.001$ & $420 \pm 373$ & $<0.001$ & $2.4 \pm 2.9$ & 1.000 & $360 \pm 129$ & 1.000 & India & \\
\hline Balter (38) & 2017 & 307 & na & $34.0(23.0-54.0)$ & $<0.001$ & $350(230-540)$ & $<0.001$ & $6.4(3.8-10.5)$ & $<0.001$ & na & - & USA & Third Imaging configuration \\
\hline Ordiales (39) & 2017 & 195 & $29.9 \pm 5.1$ & 18.5 (na-na) & $<0.001$ & 220 (na-na) & $<0.001$ & 2.70 (na-na) & $<0.001$ & 449 (na-na) & $<0.001$ & Spain & $\begin{array}{l}\text { Period } 5 \\
\text { Optimized Imaging protocol }\end{array}$ \\
\hline Gunja (40) & 2017 & na & na & $30.2 \pm 23.5$ & $<0.001$ & na & - & $7.7 \pm 5.9$ & $<0.001$ & na & - & USA & Novel imaging system \\
\hline Faroux(41) & 2017 & 508 & $28.0 \pm 5.4$ & $12.4 \pm 13.0$ & 1.000 & $176 \pm 130$ & 1.000 & na & -10 & na & - & France & Novel imaging system \\
\hline Sciahbasi (42) & 2017 & 7631 & $28 \pm 5$ & $26(16-46)$ & $<0.001$ & na & - & $3.0(1.9-5.4)$ & $<0.001$ & na & - & $\begin{array}{l}\text { Italy, } \\
\text { Germany, USA }\end{array}$ & $\begin{array}{l}\text { Italy (4 sites), Germany (1), } \\
\text { USA (1) }\end{array}$ \\
\hline \multicolumn{14}{|l|}{ PCI } \\
\hline This Study - PCI & 2017 & 750 & $26.0 \pm 4.1$ & $25.7(12.5-49.8)$ & - & $533(243-1020)$ & - & $11.4(7.1-18.2)$ & - & $738(520-1128)$ & - & $\begin{array}{l}4 \text { hospitals, } \\
\text { India }\end{array}$ & \\
\hline Abdelaal (23) & 2014 & 93 & $28.6 \pm 5.6$ & $55(35-83)$ & $<0.001$ & na & & $9.2(5.7-15.0)$ & 1.000 & na & - & Canada & $\begin{array}{l}\text { 1. Transradial Access } \\
\text { 2.Reduced Fluoro framerate } \\
\text { group ( } 7.5 \mathrm{fps})\end{array}$ \\
\hline Nakamura (27) & 2015 & 127 & $23.2 \pm 3.7$ & $85.8(\mathrm{na}-144.3)$ & $<0.001$ & na & - & 32 (na-52.9) & $<0.001$ & 3768 (na-6025) & $<0.001$ & Japan & Upgraded Imaging system \\
\hline Bracken (25) & 2015 & 47 & $27.7(25.1-32.8)$ & $83.8(47.5-118.5)$ & $<0.001$ & $\begin{array}{l}980 \quad(627.5- \\
1370.5)\end{array}$ & $<0.001$ & $17.7(13.1-27.7)$ & $<0.001$ & $1045(877-1387)$ & $<0.001$ & USA & Dose reduction technology \\
\hline Livingstone (26) & 2015 & 75 & na & $63.6 \pm 39.4$ & $<0.001$ & na & - & $\begin{array}{l}12.49^{\mathrm{a}} \quad(3.51- \\
25.5)^{\mathrm{c}}\end{array}$ & 1.000 & na & - & India & Flat panel detector \\
\hline Sciahbasi (42) & 2016 & 5465 & $27 \pm 4$ & $66(40-109)$ & $<0.001$ & na & - & $10.4(7.0-16.5)$ & 0.9988 & na & - & $\begin{array}{l}\text { Italy, } \\
\text { Germany, USA }\end{array}$ & $\begin{array}{l}\text { Italy (4 sites), Germany (1), } \\
\text { USA (1) }\end{array}$ \\
\hline Kastrati (34) & 2016 & 208 & $29.4 \pm 6.7$ & $24.8 \pm 19.8$ & 1.000 & na & - & $11.1 \pm 7.1$ & 1.000 & na & - & Germany & $\begin{array}{l}\text { Cohort Noise Reduction } \\
\text { technology }\end{array}$ \\
\hline Tarighatnia (35) & 2016 & 74 & na & $43.4^{\mathrm{a}}(5.2-118.4)^{\mathrm{c}}$ & 0.041 & $734^{\mathrm{a}}(86-2336)^{\mathrm{c}}$ & 0.996 & $8.4^{\mathrm{a}}(1.0-21.1)^{\mathrm{c}}$ & 1.000 & na & - & Iran & Transradial access \\
\hline Tarighatnia (35) & 2016 & 74 & na & $52.8^{\mathrm{a}}(4.8-194.5)^{\mathrm{c}}$ & $<0.001$ & $855^{\mathrm{a}}(93-3464)^{\mathrm{c}}$ & 0.188 & $8.8^{\mathrm{a}}(0.9-37.1)^{\mathrm{c}}$ & 1.000 & na & - & Iran & Transfemoral access \\
\hline Jurado-Roman (32) & 2016 & 160 & $28.6 \pm 5.7$ & $123.7 \pm 91.6$ & $<0.001$ & na & - & $21.3 \pm 14.6$ & $<0.001$ & na & - & Spain & Radiation Reduction Protocol \\
\hline
\end{tabular}




\begin{tabular}{|c|c|c|c|c|c|c|c|c|c|c|c|c|c|}
\hline Author & Year & $\mathbf{N}$ & $\begin{array}{c}\text { BMI } \\
\left(\mathbf{k g} / \mathbf{m}^{2}\right)\end{array}$ & Total DAP $\left(\mathbf{G y} . \mathbf{c m}^{2}\right)$ & P-Value & $\begin{array}{l}\text { CAK } \\
(\mathbf{m G y})\end{array}$ & P-Value & $\begin{array}{c}\text { FT } \\
(\min )\end{array}$ & P-Value & $\begin{array}{l}\text { Number of exp. } \\
\text { frames }\end{array}$ & P-Value & Site/country & Details \\
\hline Hansen (31) & 2016 & 146 & $\begin{array}{l}\text { Height } \quad(\mathrm{m}): \\
1.72^{\mathrm{a}} ; \quad \text { Weight } \\
(\mathrm{kg}): 64.8^{\mathrm{a}}\end{array}$ & $106.5(67.5-143.1)$ & $<0.001$ & $1459(947-6589)$ & $<0.001$ & $17.8^{\mathrm{a}}$ & $<0.001$ & na & - & USA & $\begin{array}{l}\text { Reduced Fluoro framerate } \\
\text { group ( } 7.5 \mathrm{fps})\end{array}$ \\
\hline Didier (30) & 2016 & 130 & $26.8 \pm 4.3$ & $26.6(12.7-50.7)$ & 0.4564 & $400(188-840)$ & 1.000 & na & & na & - & France & $\begin{array}{l}\text { Cardiovascular automated } \\
\text { reduction } x \text {-ray system }\end{array}$ \\
\hline Ichimoto (43) & 2017 & 57 & $29.3 \pm 6.3$ & $17.8 \pm 13$ & 1.000 & $205 \pm 141$ & 1.000 & $5.5 \pm 3.0$ & 1.000 & na & - & USA & $\begin{array}{l}\text { PCI with Dose Tracking } \\
\text { System }\end{array}$ \\
\hline Uniyal (37) & 2017 & 50 & $\begin{array}{l}\text { Weight:77 } \pm 11 \\
\mathrm{~kg}\end{array}$ & $97.0 \pm 61.7$ & $<0.001$ & $2028 \pm 1322$ & $<0.001$ & $15.7 \pm 10.0$ & $<0.001$ & $888 \pm 384$ & 0.434 & India & \\
\hline Boland (44) & 2016 & 30 & $\begin{array}{l}\text { Weight: } 83 \pm 16 \\
\mathrm{~kg}\end{array}$ & $55.6(27.0-91.5)$ & $<0.001$ & $551(310-998)$ & 0.2216 & $7.3(5.4-11.0)$ & 1.000 & na & - & Australia & Novel imaging system \\
\hline Chon (45) & 2017 & 152 & $24.6 \pm 3.3$ & $123.4 \pm 53.7$ & $<0.001$ & $1634 \pm 718$ & $<0.001$ & $16.2 \pm 8.8$ & $<0.001$ & na & - & Korea & Radiation Reduction Protocol \\
\hline Faroux (46) & 2017 & 807 & $28.0 \pm 5.4$ & $19.94 \pm 24.9$ & 1.000 & na & - & $9.7 \pm 11.2$ & 1.000 & na & - & France & Include only period 2 (2016) \\
\hline Gislason-Lee (47) & 2017 & 131 & na & 22.9 (na-na) & 0.9844 & na & - & 12.5 (na-na) & $<0.001$ & na & - & UK & Novel imaging system \\
\hline Gunja (40) & 2017 & na & na & $73.6 \pm 59.3$ & $<0.001$ & na & -1 & $20.1 \pm 12.6$ & $<0.001$ & na & - & USA & Novel imaging system \\
\hline Ordiales (39) & 2017 & 90 & $29.9 \pm 5.1$ & 38.3 (na-na) & $<0.001$ & 473 (na-na) & 0.9844 & 8.9 (na-na) & 1.000 & 664 (na-na) & 1.000 & Spain & $\begin{array}{l}\text { Period 5; Optimized imaging } \\
\text { protocol }\end{array}$ \\
\hline \multicolumn{14}{|l|}{ CAG+PCI } \\
\hline $\begin{array}{l}\text { This Study }- \\
\text { CAG+PCI }\end{array}$ & 2017 & 715 & $25.1 \pm 3.5$ & $45.8(27.3-72.0)$ & - & $891(526-1461)$ & - & $10.6(6.7-15.1)$ & - & $962(729-1245)$ & - & $\begin{array}{l}4 \text { hospitals, } \\
\text { India }\end{array}$ & \\
\hline Didier (30) & 2016 & 228 & $26.7 \pm 4$ & $45.0(26.6-75.1)$ & 0.5888 & $672(353-1082)$ & 1.000 & na & - & na & - & France & $\begin{array}{l}\text { Cardiovascular automated } \\
\text { reduction x-ray system }\end{array}$ \\
\hline Ryckx (29) & 2016 & 1527 & na & na (na-150) & - & na (na-2014) & - & na (na-18.1) & - & na & - & Switzerland & \\
\hline Jurado-Roman (32) & 2016 & 442 & $28.6 \pm 5.7$ & $123.9 \pm 48.8$ & $<0.001$ & na & - & $16.1 \pm 9.4$ & $<0.001$ & na & - & Spain & Radiation Reduction Protocol \\
\hline Tarighatnia (35) & 2016 & 52 & na & $56.5^{\mathrm{a}}(17.8-136.1)^{\mathrm{c}}$ & 0.422 & $891^{\mathrm{a}}(251-2324)^{\mathrm{c}}$ & 1.000 & $11.2^{\mathrm{a}}(3.5-25.7)^{\mathrm{c}}$ & 1.000 & na & - & Iran & Transradial access \\
\hline Tarighatnia (35) & 2016 & 52 & na & $67.4^{\mathrm{a}}(17.5-186.1)^{\mathrm{c}}$ & $<0.001$ & $\begin{array}{l}1041^{\mathrm{a}} \\
2545)^{\mathrm{c}}\end{array}$ & 0.996 & $10.8^{\mathrm{a}}(2.4-42.3)^{\mathrm{c}}$ & 1.000 & na & - & Iran & Transfemoral access \\
\hline Faroux (46) & 2017 & 441 & $28.0 \pm 5.4$ & $26.7 \pm 20.0$ & 1.000 & $471 \pm 130$ & 1.000 & na & - & na & - & France & Novel imaging system \\
\hline
\end{tabular}

Note. Radiation data values are given as median (IQR) and BMI as mean ${ }_{\star}$ standard deviation; unless otherwise indicated. 
CAK: cumulative air kerma; DAP: dose area product; FT: fluoroscopy time

${ }^{\mathrm{a}}$ Mean; ${ }^{\mathrm{c}}$ Range; ${ }^{\mathrm{d}}$ Dose Reference Level (based on 75 th Percentile); na: not available.

p-value from non-parametric 1 sample sign test when referenced data provided as median and 1 sample t test when referenced data provided as mean 